\title{
Asymmetric addition of chiral methylmagnesium alkoxides to benzaldehyde
}

\author{
William F. Bailey* and Mark R. Luderer \\ Department of Chemistry, University of Connecticut, 55 North Eagleville Road, Storrs, \\ Connecticut 06269 USA \\ E-mail: William.Bailey@uconn.edu
}

\section{Dedicated to Drs. Cynthia and Bruce Maryanoff}

\begin{abstract}
The ability of chiral methylmagnesium alkoxides derived from enantiopure alcohols to effect asymmetric addition to benzaldehyde has been investigated. The addition to benzaldehyde of chiral methylmagnesium alkoxides prepared from (-)-borneol, (+)-menthol or (+)-Nmethylpseudoephedrine afforded virtually racemic 1-phenylethanol. Equilibration of a more complex species, generated upon addition of one molar equiv of MeMgBr to various molar quantities of the dilithio salt of (+)-pseudoephedrine before addition of benzaldehyde had a dramatic effect on both the reactivity of the reagent and the enantioselectivity of the addition.
\end{abstract}

Keywords: Asymmetric addition, alkylmagnesium alkoxides, aggregation, Grignard

\section{Introduction}

There is a rich literature detailing attempts to effect enantioselective addition of Grignard reagents and related main-group organometallics to achiral carbonyl substrates in the presence of a chiral ligand or solvent. ${ }^{1}$ The synthesis of the Merck reverse transcriptase inhibitor Efavirenz ${ }^{\circledR}$, by highly enantioselective addition (in 95\% yield with an ee of $>98 \%$ ) of lithium cyclopropylacetylide to an achiral ketone in the presence of an $N$-pyrrolidinylnorephedrine ligand, arguably represents the state-of-the-art in asymmetric addition of an organolithium to a carbonyl substrate. ${ }^{2}$ A major difficulty in designing an effective and general method for effecting asymmetric addition of a main-group organometallic to an achiral aldehyde or ketone in the presence of a chiral additive is the background reaction: uncomplexed Grignard reagents, dialkylmagnesiums, and alkyllithiums react rapidly with such substrates.

It occurred to us that chiral alkylmagnesium alkoxides might prove useful for asymmetric addition to carbonyl compounds. An exploratory study of the reactions of several chiral 
methylmagnesium alkoxides with benzaldehyde, detailed below, suggests that the aggregation state of the reagents may have a dramatic effect on the enantioselectivity of the process.

Alkylmagnesium alkoxides have been prepared, as illustrated below, by reaction of a dialkylmagnesium with an alcohol (eq. 1) ${ }^{3}$ or by treatment of a Grignard reagent with an alkoxide (eq. 2). ${ }^{4}$ The groups of Coates $^{3}$ and Ashby ${ }^{5}$ have investigated the rather complex solution-state structures of various alkylmagnesium alkoxides. The aggregation states of these reagents were found to be dependent on solvent, steric bulk, concentration and temperature. It is relevant to the results discussed below that interconversion among the aggregates of alkylmagnesium alkoxides may be quite slow. For example, Ashby and coworkers observed a change in aggregation when methylmagnesium tert-butoxide was heated at reflux in diethyl ether: the dimeric structure that initially formed rearranged to a thermodynamically more stable cubane-like tetramer and, at room temperature, the half-time for this conversion was 30 days. ${ }^{5}$

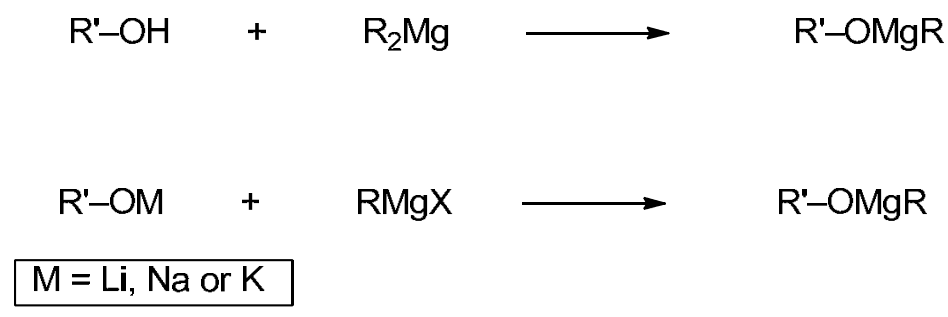

Alkylmagnesium alkoxides are generally less reactive than are the analogous dialkymagnesium reagents and are approximately as reactive as the corresponding Grignard reagent. ${ }^{6}$ Not surprisingly, the outcome of reactions of alkylmagnesium alkoxides with carbonyl compounds parallels that of dialkymagnesiums and Grignard reagents. ${ }^{7}$

\section{Results and Discussion}

Given these preliminaries, the ability of chiral alkylmagnesium alkoxides to effect asymmetric addition to benzaldehyde was explored. The chiral alkylmagnesium alkoxides were prepared from enantiopure chiral alcohols by reaction with dimethylmagnesium ${ }^{7}$ as illustrated in Scheme 1. The results of addition of several chiral alkylmagnesium alkoxides to benzaldehyde (Scheme 1) are summarized in Table 1 . The enantioselectivity of the reactions was assessed by analysis of the 1-phenylethanol 1 product via chiral stationary phase HPLC (CSP-HPLC) on a 25-cm x 0.46cm Chiralcel OD column (Daicel Chemical Industries). Using a flow rate of $0.5 \mathrm{~mL} / \mathrm{min}$ and a mobile phase of $98 \%$ hexane - 2\% 2-propanol, the enantiomers of 1-phenylethanol 1 had retention times $\left(\mathrm{t}_{\mathrm{R}}\right)$ of $24.9 \mathrm{~min}$ and $28.0 \mathrm{~min}$. 


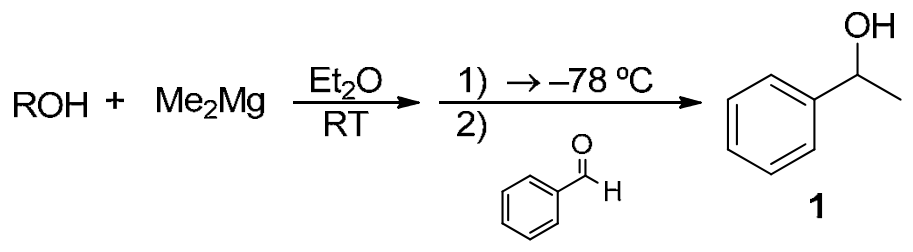

3) $\mathrm{aq} \mathrm{NH} \mathrm{NH}_{4} \mathrm{Cl}$

\section{Scheme 1}

Table 1. Addition of chiral methylmagnesium alkoxides to benzaldehyde (Scheme 1).

Entry

${ }^{a}$ Yields based on GC/FID and are uncorrected. ${ }^{\mathrm{b}}$ Er from CSP-HPLC analysis on a Chiralcel OD column with a flow rate of $0.5 \mathrm{~mL} / \mathrm{min}$ and a mobile phase of $98 \%$ hexane: 2 -propanol: $\mathrm{t}_{\mathrm{R} 1}=$ $24.9 \mathrm{~min}, \mathrm{t}_{\mathrm{R} 2}=28.0 \mathrm{~min}$.

Only very slight enantioselectivity was observed using the alkoxide derived from (-)-borneol (Table 1, entry 1), while alkoxides derived from $(1 S, 2 R, 5 S)-(+)$-menthol (Table 1 , entry 2$)$ or $(1 S, 2 S)-(+)-N$-methylpseudoephedrine (Table 1 , entry 3$)$ afforded racemic product.

The methylmagnesium alkoxides derived from (-)-borneol and (+)-menthol were also prepared by treatment of methylmagnesium bromide with the corresponding sodium alkoxides ${ }^{4}$ in THF solvent. These reagents were much less reactive than those prepared from dimethylmagnesium; in fact, no reaction with benzaldehyde (addition or reduction) occurred at room temperature (Scheme 2). 

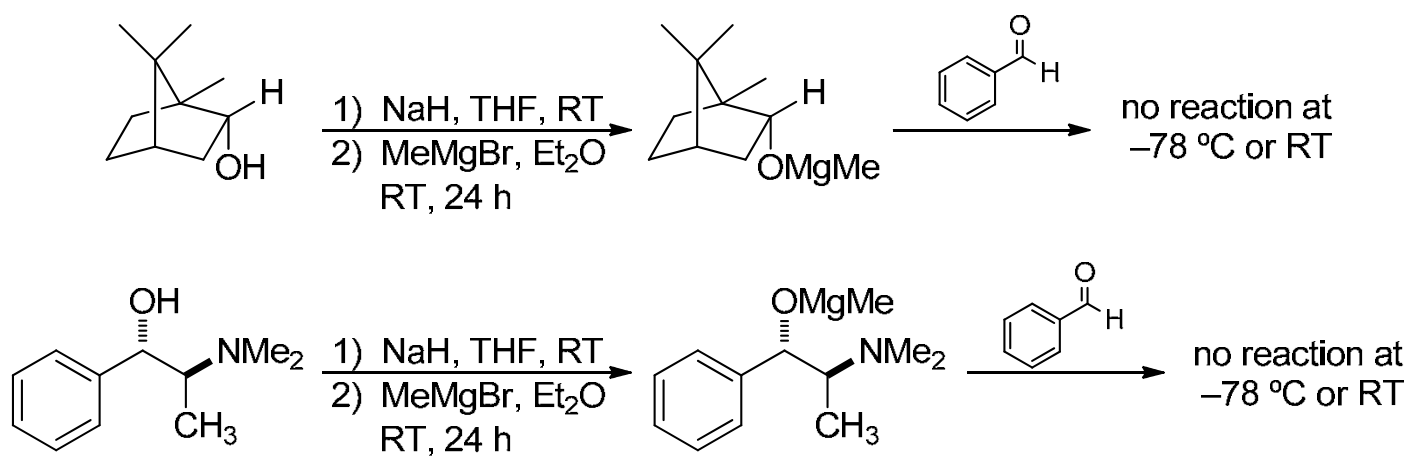

\section{Scheme 2}

In light of the observation that simple chiral methylmagnesium alkoxides displayed little or no enantioselectivity in the addition to benzaldehyde, it seemed worthwhile to investigate the behavior of a more complex reagent derived from the reaction of the dilithio salt of $(1 S, 2 S)-(+)-$ pseudoephedrine with one molar equivalent of either methylmagnesium bromide or dimethylmagnesium. The structure (or structures) of the species generated when methylmagnesium bromide or dimethylmagnesium is added to the dilithium salt of $(+)$ pseudoephedrine is uncertain; nonetheless, as illustrated in Scheme 3, the reagents react cleanly with benzaldehyde to give a high yield of 1-phenylethanol. Unfortunately, the alcohol product is racemic.
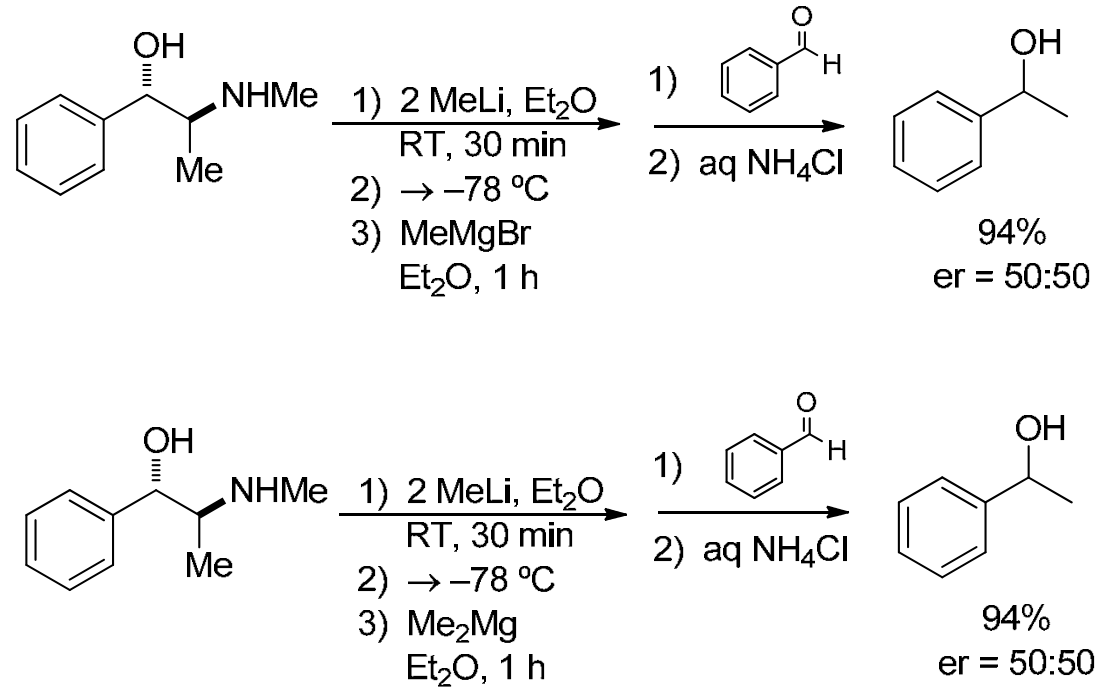

\section{Scheme 3}

As noted above, interconversion among the aggregates of alkylmagnesium alkoxides is slow and the initially generated aggregate may not be the most stable structure. Moreover, the lithium cyclopropylacetylide - ligand complexes employed during Merck’s work on Efavirenz ${ }^{\circledR}$ were 
dramatically more effective as chiral ligands when allowance was made for the formation of a more stable aggregate. ${ }^{2}$ In view of this precedent, an investigation was undertaken to determine whether a similar situation might apply in the present case.

Allowing solutions of the species generated upon addition of one molar equiv of methylmagnesium bromide to various molar quantities of the dilithio salt of $(1 S, 2 S)-(+)-$ pseudoephedrine, in either diethyl ether or THF solution, to equilibrate at different times and temperatures before addition of benzaldehyde had a dramatic effect on both the reactivity of the reagent and the enantioselectivity of the addition. The results of these exploratory experiments are summarized in Table 2.

The yields of both 1-phenylethanol $\mathbf{1}$ and benzyl alcohol $\mathbf{2}$ obtained from these experiments were often quite low (Table 2, entries 5-7, 9 and 10) and benzaldehyde was recovered from such reaction mixtures. While reduction of benzaldehyde to benzyl alcohol 2 was somewhat unexpected, it is perhaps not surprising given that alkali metal alkoxides are known to reduce aldehydes (Meerwein-Ponndorf-Verley reduction). ${ }^{8}$

Cursory inspection of the results of these experiments (Table 2) reveals that the reagent obtained upon equilibration, either at room temperature or at reflux, is much less reactive than is the species obtained initially on mixing $\mathrm{MeMgBr}$ with a molar equiv of the dilithio salt of $(+)-$ pseudoephedrine (Scheme 3): clearly, the equilibrated reagent is fundamentally different than the organometallic generated initially by combining equimolar quantities of $\mathrm{MeMgBr}$ and the dilithio salt. Most notably, however, the enantioselectivity of the addition reaction is increased when the reagent obtained from one molar equiv of $\mathrm{MeMgBr}$ and 5 molar equiv of the dilithio salt of (+)-pseudoephedrine in $\mathrm{Et}_{2} \mathrm{O}$ is allowed to equilibrate for $24 \mathrm{~h}$ prior to reaction with benzaldehyde (Table 2, entries 6 and 7).

While it is clear from the results of these experiments that allowing solutions of methylmagnesium bromide and the dilithio salt of (+)-pseudoephedrine to equilibrate before addition of benzaldehyde alters both the reactivity and the enantioselectivity of the reagent, the origin of these effects is not at all apparent. Since nothing is known concerning the structure of these reagents, any discussion of the results would be highly speculative. 
Table 2. Addition to benzaldehyde of the species generated upon addition of methylmagnesium bromide to the dilithio salt of $(1 S, 2 S)-(+)$-pseudoephedrine.

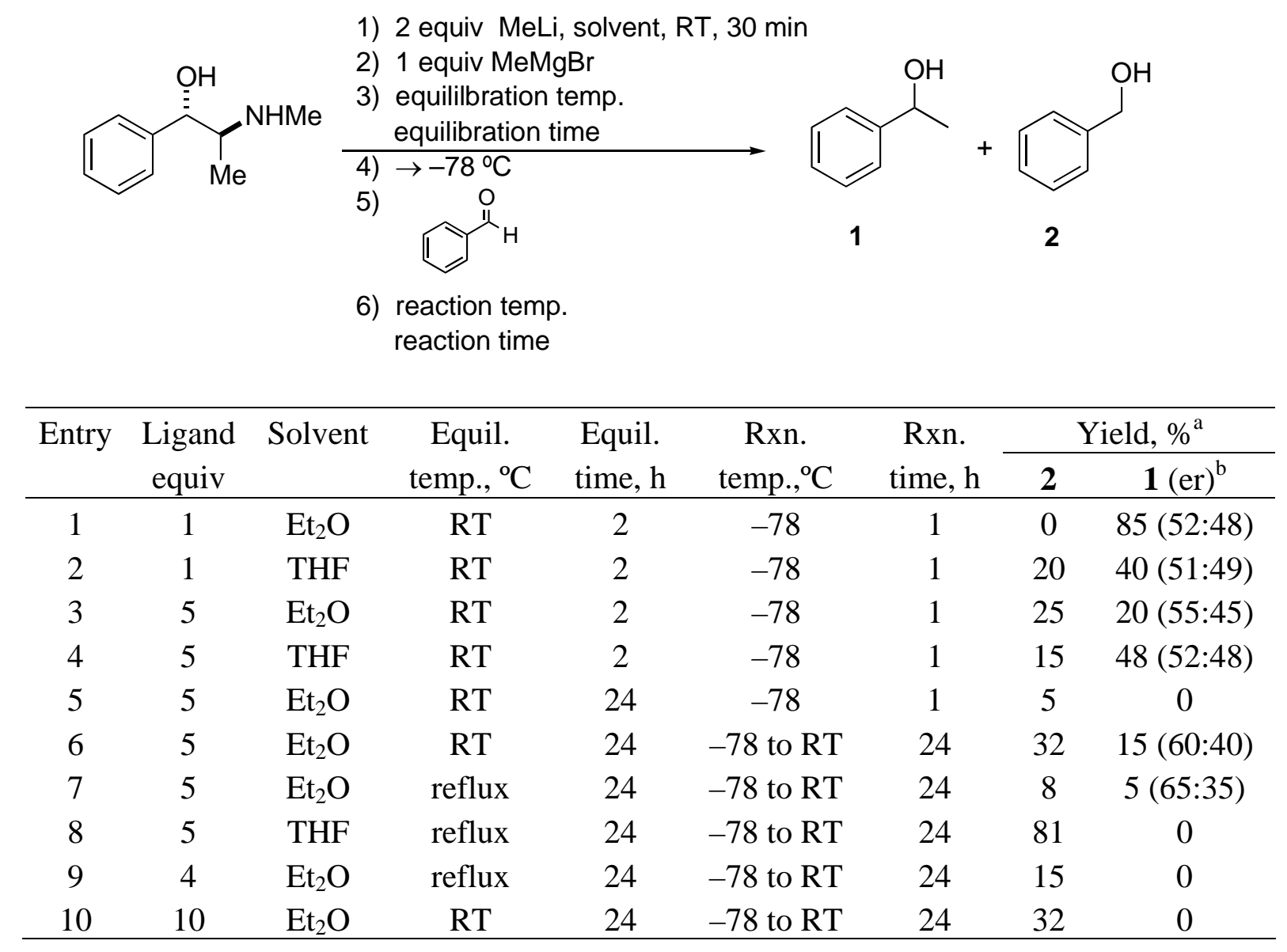

a Yields based on GC/FID and are uncorrected; the balance of the reaction mixtures contained unreacted benzaldehyde. ${ }^{\mathrm{b}}$ Er from CSP-HPLC analysis on a Chiralcel OD column with a flow rate of $0.5 \mathrm{~mL} / \mathrm{min}$ and a mobile phase of $98 \%$ hexane: 2 -propanol: $\mathrm{t}_{\mathrm{R} 1}=24.9 \mathrm{~min}, \mathrm{t}_{\mathrm{R} 2}=28.0$ $\min$.

\section{Experimental Section}

General Procedures. Manipulations of organometallic reagents were performed in flame-dried glassware under an atmosphere of " 0 ” grade argon using standard syringe techniques. Grignard reagents were prepared by standard methods ${ }^{9}$ and their concentrations were determined immediately prior to use as described by Watson and Eastham ${ }^{10}$ by titration with a standard solution of 2-butanol in xylenes using 1,10-phenanthroline as indicator. Anhydrous diethyl ether and THF were freshly distilled from a dark-purple solution of sodium and benzophenone. Gasliquid chromatography (GC) was performed on a Hewlett-Packard 5890 gas chromatograph 
equipped with a flame-ionization detector and fitted with a HP-5, 25-m x 0.2-mm x $0.33 \mu \mathrm{m}$ film thickness fused-silica glass capillary column. Chiral stationary phase-high pressure liquid chromatography (CSP-HPLC), used for determination of enantiomeric purity, was conducted on a $25-\mathrm{cm}$ x $0.46-\mathrm{cm}$ Chiralcel OD (Daicel Chemical Industries, Ltd.) column. ${ }^{1} \mathrm{H}$ and ${ }^{13} \mathrm{C}$ NMR spectra were obtained on a Bruker DRX-400 spectrometer using $\mathrm{CDCl}_{3}$ as solvent. Proton spectra are referenced at $\delta=0$ for internal tetramethylsilane while carbon spectra are referenced at $\delta=77.26$ for ${ }^{13} \mathrm{CDCl}_{3}$ and are reported versus TMS at $\delta=0$.

Preparation of alkylmagnesium alkoxides by reaction of dimethylmagnesium with an alcohol and their reaction with benzaldehyde. Following the procedure of Ashby and Willard, ${ }^{7} 1.0$ molar equivalent of a $1.0 \mathrm{M}$ solution of the appropriate alcohol in diethyl ether was added under argon to 1.0 molar equivalent of dimethylmagnesium ${ }^{11}$ in diethyl ether. Upon completion of the addition, the resulting cloudy solution was allowed to stir for 45 min at room temperature, cooled to $-78{ }^{\circ} \mathrm{C}$, then 1.0 molar equivalent of a $1.0 \mathrm{M}$ solution of benzaldehyde in diethyl ether was added dropwise. The resulting solution was stirred for $1 \mathrm{~h}$ at $-78{ }^{\circ} \mathrm{C}$ before quenching with saturated, aqueous ammonium chloride. The aqueous phase was discarded and the organic phase was washed with $25 \mathrm{~mL}$ of water, $25 \mathrm{~mL}$ of brine, dried $\left(\mathrm{MgSO}_{4}\right)$ and concentrated by rotary evaporation. The residue was analyzed by GC and CSP-HPLC. Products were identified by comparison of retention times and mass spectra with those of authentic samples. The results are summarized in Table 1.

Preparation of alkylmagnesium alkoxides by reaction of a sodium alkoxide with methylmagnesium bromide and their reaction with benzaldehyde. Following the procedure of Narula and coworkers, ${ }^{4} 1.0$ molar equivalent of the appropriate alcohol, sufficient THF to produce a $1.0 \mathrm{M}$ solution, and 1.0 molar equivalent of oil-free sodium hydride were stirred at room temperature for $1 \mathrm{~h}$ followed by the addition of 1.0 molar equivalent of methylmagnesium bromide in diethyl ether. The resulting solution was then stirred for $24 \mathrm{~h}$ at room temperature. The solution was cooled to $-78{ }^{\circ} \mathrm{C}$ and 1.0 molar equivalent of a $1.0 \mathrm{M}$ solution of benzaldehyde in diethyl ether was added dropwise. The reaction mixture was stirred for $24 \mathrm{~h}$ at room temperature. The solution was then quenched with saturated, aqueous ammonium chloride, the THF was removed by rotary evaporation, and the residue was partitioned between $50 \mathrm{~mL}$ of water and $50 \mathrm{~mL}$ of diethyl ether. The aqueous phase was discarded and the organic layer was washed with $25 \mathrm{~mL}$ of water, $25 \mathrm{~mL}$ of brine, dried $\left(\mathrm{MgSO}_{4}\right)$, and concentrated by rotary evaporation. The residue was analyzed by GC and CSP-HPLC. Products were identified by comparison of retention times and mass spectra with those of authentic samples. The results are summarized in Scheme 2.

Exploration of the effect of the dilithio salt of pseudoephedrine on the reactivity and enantioselectivity of Grignard additions to benzaldehyde. A flame-dried, round-bottomed flask was charged under argon with the appropriate quantity of $(1 S, 2 S)-(+)$-pseudoephedrine (Table 2) and sufficient solvent to produce a $0.1 \mathrm{M}$ solution, and 2.0 molar equivalents of MeLi in diethyl ether was added dropwise at room temperature. The resulting solution was stirred at 
room temperature for $30 \mathrm{~min}$ before addition of 1.0 molar equivalent of methylmagnesium bromide. The solution was then brought to the desired temperature and stirred for the appropriate equilibration time (Table 2) before dropwise addition of 1.0 molar equivalent of $1.0 \mathrm{M}$ solution of benzaldehyde in diethyl ether. Reaction mixtures were stirred at $-78{ }^{\circ} \mathrm{C}$ or room temperature for the appropriate time (Table 2) before quenching with saturated, aqueous ammonium chloride. The aqueous phase was discarded, and the organic layer was washed with $25 \mathrm{~mL}$ of water, $25 \mathrm{~mL}$ of $10 \%(\mathrm{w} / \mathrm{v})$ of aqueous $\mathrm{HCl}, 25 \mathrm{~mL}$ of brine, dried $\left(\mathrm{MgSO}_{4}\right)$, and concentrated by rotary evaporation. The residue was analyzed by GC and CSP-HPLC; products were identified by comparison of their retention times and mass spectra with those of authentic samples. The results are summarized in Table 2.

\section{Acknowledgements}

This work was supported by a grant from the Process Chemistry Division, H. Lundbeck A/S, Copenhagen, Denmark. We are grateful to Drs. Michael Bech Sommer and Robert J. Dancer for helpful discussions.

\section{References}

1 For a recent review, see: Luderer, M. R.; Bailey, W. F.; Luderer, M. R.; Fair, J. D.; Dancer, R. J.; Sommer, M. B. Tetrahedron: Asymmetry 2009, 20, 981.

2 (a) Ye, M.; Logarai, K S.; Jackman, L. M.; Hillegass, K.; Hirsh, K.; Bollinger, A. M.; Grosz, A .L.; Mani, V. Tetrahedron 1994, 50, 6109. (b) Thompson, A.; Corley, E. G.; Huntingdon, M. F.; Grabowski, E .J. J.; Remenar, J. F.; Collum, D. B. J. Am. Chem. Soc. 1998, 120, 2028. (c) Xu, F.; Reamer, R. A.; Tillyer, R.; Cummins, J. M.; Grabowski, E. J. J.; Reider, P. J.; Collum, D. B.; Huffman, J. C. J. Am. Chem. Soc. 2000, 122, 11212. (d) Grabowski, J .J .E. Chirality 2005, 17, S249.

3 Coates, G. E.; Heslop, J. A.; Redwood, M. E.; Ridley, D. J. Chem. Soc. A 1968, 1118.

4 Gupta, S.; Sharma, S.; Narula, A. K. J. Organomet. Chem. 1993, 452, 1.

5 Ashby, E. C.; Nackashi, J.; Parris, G.E. J. Am. Chem. Soc. 1975, 97, 3162.

6 House, H. O.; Latham, R. A.; Whitesides, G. M. J. Org. Chem. 1967, 32, 2481.

7 Ashby, E. C.; Willard, G. F. J. Org. Chem. 1978, 43, 4094.

8 For a discussion of the Meerwein-Ponndorf-Verley reduction, see Kürti, L.; Czakó, B. Strategic Applications of Named Reactions in Organic Synthesis, Academic Press, Amsterdam, 2005, pp 280-281.

9 Wakefield, B. J. Organomagnesium Methods in Organic Synthesis; Academic Press: San Diego, 1995.

10 Watson, S. C.; Eastham, J. F. J. Organomet. Chem. 1997, 62, 3542.

11 Burns, T. P.; Rieke, R. D. J. Org. Chem. 1987, 52, 3674. 